\title{
Glycosylated Hemoglobin levels and the Risk for Contrast-Induced Nephropathy in Diabetic Patients Undergoing Coronary arteriography/Percutaneous Coronary Intervention
}

\author{
hong Zhang \\ Tianjin Chest Hospital \\ han Fu \\ Tianjin Medical University \\ jing Zhang \\ Tianjin Chest Hospital \\ peng Zhang \\ Tianjin Chest Hospital \\ shicheng Yang \\ Tianjin Chest Hospital \\ xiaofeng Fu \\ Tianjin Medical University \\ zhican Zeng \\ Tianjin Medical University \\ naikuan fu ( $\nabla$ cdrfnk@163.com) \\ Tianjin Chest Hospital
}

Research article

Keywords: diabetes mellitus, glycosylated hemoglobin, percutaneous coronary intervention, contrastinduced nephropathy, risk factors

Posted Date: February 9th, 2021

DOl: https://doi.org/10.21203/rs.3.rs-199386/v1

License: (c) (i) This work is licensed under a Creative Commons Attribution 4.0 International License. Read Full License 


\section{Abstract}

Backgrounds: Diabetes mellitus is an independent risk factor for Contrast-induced nephropathy $(\mathrm{CIN})$ in patients undergoing Coronary arteriography (CAG)/percutaneous coronary intervention ( $\mathrm{PCl}$ ). Glycosylated hemoglobin (HbA1c) is the gold standard to measure blood glucose control, which has important clinical significance for evaluating blood glucose control in diabetic patients in the past 3 months. This study aimed to evaluate whether preoperative hemoglobin a1c levels in diabetic patients who received $\mathrm{CAG} / \mathrm{PCI}$ had an impact on the occurrence of postoperative $\mathrm{CIN}$.

Methods: We reviewed the incidence of preoperative $\mathrm{HbA} 1 \mathrm{c}$ and postoperative $\mathrm{CIN}$ in 670 patients with CAG/PCI from January 1, 2020 to October 30,2020, and divided the preoperative HbA1c levels into 5 groups. Blood samples were collected at admission, $48 \mathrm{~h}$ and $72 \mathrm{~h}$ after operation to measure the Scr value of patients. Categorical variables were compared using a chi-square test, and continuous variables were compared using an analysis of variance. Fisher's exact test was used to compare the percentages when the expected frequency was less than 5 . Multivariable logistic regression analysis was used to exclude the influence of confounding factors and $\mathrm{P}$ for trend was used to analyze the trend between $\mathrm{HbA} 1 \mathrm{c}$ levels and the increased risk of $\mathrm{CIN}$.

Results: Patients with elevated $\mathrm{HbA1c}$ had higher BMI, FBG and LDL-C, and they were more often on therapy with hypoglycemic agents, Insulin and PCl. They also had higher basal, $24 \mathrm{~h}$ and $48 \mathrm{~h} \mathrm{Scr}$. (Table 1) The incidence of $\mathrm{CIN}$ in the 5 groups of patients were: $9.8 \%, 11.9 \%, 15.2 \%, 25.3 \%, 48.1 \%$. $(p<0.0001)$ The multivariate analysis confirmed that in the main high-risk subgroup, patients with elevated HbA1C levels ( $\geq 8.8 \%$ ) had a higher risk of CIN disease. (Figure 2) Trend test showed the change of HR $(1.000,1.248,1.553,2.625,5.829)$. (Table 2)

Conclusions: Studies have shown that in diabetic patients undergoing $\mathrm{CAG} / \mathrm{PCl}$, elevated $\mathrm{HbA} 1 \mathrm{C}$ is independently associated with the risk of $\mathrm{CIN}$, and with the increase of $\mathrm{HbA} 1 \mathrm{C}$ level, the incidence of $\mathrm{CIN}$ gradually increases.

\section{Introduction}

Contrast-induced nephropathy $(\mathrm{CIN})$ is reversible acute renal failure observed after administration of iodinated contrast media (CM) during angiographic or other medical procedures and is defined as an increase of $25 \%$ or more, or an absolute increase of $0.5 \mathrm{mg} / \mathrm{dL}$ or more in serum creatinine (Scr) from baseline value, at 48 to 72 hours following the exposure to CM. $(1,2)$ The exact mechanism of CIN is unclear, and it may be related to hemodynamic effects, the formation of reactive oxygen species (ROS) and renal tubular cytotoxicity. (3)In addition, studies have shown that inflammation, immune response, and the decrease in the number of endothelial progenitor cells (EPCs) will also affect the occurrence of CIN. (4-6)Many risk factors may contribute to the development of contrast nephropathy, such as age, glomerular filtration rate, preoperative hyperglycemia at blood cholesterol admission, and elevated glycosylated hemoglobin, both associated with $\mathrm{CIN} .(7,8)$ The key to reducing the incidence of $\mathrm{CIN}$ is to 
identify patients at high risk of $\mathrm{CIN}$ and to adopt appropriate prevention programs. Studies have found that patients with diabetes have a higher risk of CIN. Diabetic nephropathy has been identified as a powerful and independent risk factor for CIN. (9) Both diabetes and the administration of iodinated radiocontrast agents are both associated with marked alterations of renal physiology, including changes in GFR and renal hemodynamics, enhanced tubular transport activity and oxygen expenditure and intensification of medullary hypoxia, and ROS generation.(10) Long-term hyperglycemia will cause many pathophysiological changes, such as endothelial and microvascular dysfunction, increased production of vascular inflammatory markers and ROS, and impaired immune response. (11) Measurements of glycosylated hemoglobin ( $\mathrm{HbA1c}$ ) can provide an average blood glucose level for the past 2-3 months and adequately reflect glycemic control in patients with diabetes.(12)Current studies have shown that among patients without diabetes undergoing CAG/PCl elevated $\mathrm{HbA} 1 \mathrm{c}$ is independently associated with the risk of $\mathrm{CIN}$. (13)However, there is no more data to confirm whether the level of HbA1c in patients with existing diabetic patients affects the occurrence of $\mathrm{CIN}$, and most prior studies have focused predominantly on the prognostic value of admission glucose, which represents only a single measurement in time. Therefore, compared with previous clinical trials, our study aims to focus on whether the level of $\mathrm{HbA} 1 \mathrm{c}$ in diabetic patients undergoing $\mathrm{CAG} / \mathrm{PCl}$ is related to the risk of $\mathrm{CIN}$, and a prospective trial was conducted in diabetic patients receiving $\mathrm{CAG} / \mathrm{PCl}$.

\section{Method}

\section{Study population}

We initially assessed 833 patients who underwent CAG/PCI. Inclusion criteria were as follows: Patients who meet the diagnostic criteria for diabetes and underwent CAG/PCI. [The American Diabetes Association (ADA) defines Criteria for the diagnosis of diabetes: (1) fasting plasma glucose (FPG) > $126 \mathrm{mg} / \mathrm{dL}(7.0 \mathrm{mmol} / \mathrm{L}) ;(2) 2 \mathrm{~h}$ plasma glucose $(\mathrm{PG})>200 \mathrm{mg} / \mathrm{dL}(11.1 \mathrm{mmol} / \mathrm{L})$ during oral glucose tolerance test (OGTT); (3) HbA1c > 6.5\% (48 mmol/mol); (4) In a patient with classic symptoms of hyperglycemia or hyperglycemic crisis, a random plasma glucose $>200 \mathrm{mg} / \mathrm{dL}(11.1 \mathrm{mmol} / \mathrm{L})]$. (14)Exclusion criteria were acute ST-segment elevation myocardial infarction (STEMI) receiving emergency $\mathrm{PCl}$, receiving $\mathrm{CM} 14$ days before $\mathrm{PCl}$, hypotension (systolic blood pressure $<90 \mathrm{mmHg}$ ), using any renal toxicity drugs during the perioperative period, severe renal insufficiency (creatinine clearance < $30 \mathrm{~mL} / \mathrm{min}$ ) or severe cardiac insufficiency (left ventricular ejection fraction (LVEF) $<30 \%$ ), cardiogenic shock and heart failure, hypersensitivity to $\mathrm{CM}$, severe liver damage, autoimmune diseases, malignant tumor, infectious diseases or fever. We also exclude other conditions that may affect $\mathrm{HbA} 1 \mathrm{c}$ : hemoglobinopathy, pregnancy, uremia, blood transfusion and hemolytic anemia.(15) (Fig. 1) The present study was approved by the Ethics Committee of the Tianjin Chest Hospital and written informed consent was obtained from all participates before enrollment.

Figure 1. CAG: HbA1c: glycosylated hemoglobin; Coronary arteriography PCl; percutaneous coronary intervention; Scr: serum creatinine; CIN: contrast-induced nephropathy. 
We finally evaluated 670 diabetic patients undergoing CAG/PCI. The study protocol conforms to the ethical guidelines of the 1975 Declaration of Helsinki as reflected in a priori approval by the institution's human research committee. Patients were stratified into 5 pre-procedural HbA1c groups: $<6.5 \%$; $6.5-8 \%$; $8-9.5 \% ; 9.5-11 \% ;>11 \%$. Because related studies have proved that hydration in the perioperative period is effective in preventing the occurrence of $\operatorname{CIN}(16,17)$, all patients received isotonic saline $(0.9 \%$ sodium chloride) 12 hours before and after surgery and supplemented with standard hydration solution (at least $1,000 \mathrm{~mL}$ ) at a rate of $1 \mathrm{~mL} / \mathrm{kg} / \mathrm{h}$. Hydration rate was reduced to $0.5 \mathrm{~mL} / \mathrm{kg} / \mathrm{h}$ for patients with $\mathrm{LVEF} \leqslant 45 \%$. All patients were given aspirin and clopidogrel loading dose $300 \mathrm{mg}$ before surgery. Clinicians can decide whether to use the following medicines based on clinical requirements or guidelines, including b-blockers, angiotensin converting enzyme inhibitors (ACEls)/angiotensin II receptor blockers (ARBs), calcium channel blockers (CCBs), diuretics, and statin.

The risk of $\mathrm{CIN}$ is related to $\mathrm{CM}$ osmotic pressure. lodine contrast agents include low-osmotic contrast media (LOCM), iso-osmotic contrast media, and high-osmotic contrast media. (18)Isotonic contrast agents are more effective than LOMC in reducing the incidence of CIN in patients. (19)Therefore, patients with normal and mildly abnormal Scr levels (Scr $\leqslant 177 \mu \mathrm{mol} / \mathrm{L})$ before surgery are treated with iopromide (LOCM). Compared with other CMs, iodixanol (isotonic contrast agent) has less nephrotoxicity, lower risk of cardiovascular adverse events, and thermal discomfort and is used in patients with moderately and severely abnormal Scr level $(\mathrm{Scr}>177 \mu \mathrm{mol} / \mathrm{L})(20,21)$ There was no statistically significant difference in the number of patients using contrast media between the five groups. $(P=0.261)$

Study endpoints

Blood samples were collected at admission, $48 \mathrm{~h}$ and $72 \mathrm{~h}$ after operation to measure the Scr value of patients. The primary study end point was CIN, diagnosed by the highest Scr concentrations 48 and 72 hours after $\mathrm{CM}$ exposure. Additional clinical endpoints included: Adverse events during hospitalization and 14-day follow-up, included all-cause mortality, hypotension or severe decrease in blood pressure, acute heart failure, coronary artery bypass, and graft cerebrovascular events.

\section{Statistical analysis}

Results are expressed as numbers (\%) or mean \pm SD. Compare means between five groups: categorical variables were compared using a chi-square test, and continuous variables were compared using an analysis of variance. Fisher's exact test was used to compare the percentages when the expected frequency was less than 5 . Multivariable logistic regression analysis was used to exclude the influence of confounding factors, and to evaluate whether the association between pre-procedural $\mathrm{HbA} 1 \mathrm{c}$ values and CIN persisted after adjustment for other patient characteristics and potential confounders. $P$ for trend was used to analyze the trend between $\mathrm{HbA} 1 \mathrm{c}$ levels and the increased risk of CIN. All statistical data were analyzed by SPSS software 22.0. 


\section{Results}

Baseline clinical characteristics

There were no significant differences between the five groups in the baseline characteristics (Age, Male, Smoking, LVEF, Hypertension, Contrast volume, Hemoglobin, TG, TC, HDL-C, Hydration amount, Aspirin, Clopidogrel, b-blockers, ACEI/ARB, Diuretics, CCBs) before operation. Patients with elevated HbA1C levels had higher LDL levels $(p=0.010)$, BMI $(p<0.001)$ and Preoperative FBG $(p<0.001)$. In addition, patients with higher levels of HbA1C were more often on therapy with hypoglycemic agents $(p=0.033)$, Insulin ( $p$ $=0.011)$ and PCI. $(p=0.027)($ Table 1$)$ 
Table 1

Comparisons of baseline characteristics between the two groups.

\begin{tabular}{|c|c|c|c|c|c|c|}
\hline Variables & $\begin{array}{l}\mathrm{HbA} 1 \mathrm{c}<6.5 \% \\
(\mathrm{n}=82)\end{array}$ & $\begin{array}{l}\mathrm{HbA} 1 \mathrm{c} 6.5- \\
8 \% \\
(n=236)\end{array}$ & $\begin{array}{l}\text { HbA1c8- } \\
9.5 \% \\
(n=197)\end{array}$ & $\begin{array}{l}\mathrm{HbA} 1 \mathrm{c} 9.5 \% \\
\text { to11\% } \\
(\mathrm{n}=99)\end{array}$ & $\begin{array}{l}\text { HbA1c>11\% } \\
(n=27)\end{array}$ & $\mathbf{P}$ \\
\hline Age (years) & $66.61 \pm 7.13$ & $\begin{array}{l}67.78 \pm \\
6.08\end{array}$ & $\begin{array}{l}67.06 \pm \\
7.42\end{array}$ & $\begin{array}{l}66.55 \pm \\
751\end{array}$ & $\begin{array}{l}68.93 \pm \\
5.78\end{array}$ & 0.296 \\
\hline Male (\%) & 43(52.4) & & & & & 0.767 \\
\hline Smoking (\%) & $59(72.0)$ & $112(+7.0)$ & (U) (U) & $4(4+4)$ & $v(40.1)$ & 0.778 \\
\hline LVEF & $61.12 \pm 6.52$ & ) (0.0. & 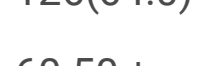 & ) & ) & 0.445 \\
\hline Hypertension & $40(48.8)$ & 7.29 & $\begin{array}{l}60.50 \pm \\
6.96\end{array}$ & $\begin{array}{l}59.87 \pm \\
7.31\end{array}$ & $\begin{array}{l}5.97 \pm \\
5.97\end{array}$ & 0.140 \\
\hline & $24.62 \pm 2.28$ & $129(54.7)$ & 118(59.9) & $65(65.7)$ & 16(74.1) & $<$ \\
\hline BMI $\left(\mathrm{kg} / \mathrm{m}^{2}\right)$ & $\begin{array}{l}168.90 \pm \\
58.44\end{array}$ & $\begin{array}{l}24.90 \pm \\
2.09\end{array}$ & $\begin{array}{l}25.27 \pm \\
1.85\end{array}$ & $\begin{array}{l}25.63 \pm \\
1.80\end{array}$ & $\begin{array}{l}26.45 \pm \\
1.70\end{array}$ & $0.0001^{a}$ \\
\hline $\mathrm{TG}(\mathrm{mmol} / \mathrm{L})$ & $1.77 \pm 1.02$ & $\begin{array}{l}166.61 \pm \\
52.07\end{array}$ & $\begin{array}{l}170.91 \pm \\
62.12\end{array}$ & $\begin{array}{l}175.76 \pm \\
70.34\end{array}$ & $\begin{array}{l}175.19 \pm \\
45.27\end{array}$ & 0.512 \\
\hline $\mathrm{TC}(\mathrm{mmol} / \mathrm{L})$ & $130+038$ & $1.75 \pm 0.91$ & $1.85 \pm$ & $1.75 \pm 0.86$ & $2.06 \pm 0.87$ & 0.364 \\
\hline $\begin{array}{l}\mathrm{HDL}-\mathrm{C} \\
(\mathrm{mmol} / \mathrm{L})\end{array}$ & $2.46 \pm 0.55$ & $4.52 \pm 0.41$ & $4.61 \pm$ & $4.52 \pm 0.52$ & $4.57 \pm 0.50$ & 0.509 \\
\hline & $663+137$ & $1.24 \pm 0.33$ & 0.57 & $1.28 \pm 0.40$ & $1.26 \pm 0.25$ & $0.010^{\mathrm{a}}$ \\
\hline $\begin{array}{l}\text { LDL-C } \\
(\mathrm{mmol} / \mathrm{L})\end{array}$ & $1305.5 \pm$ & $2.49 \pm 0.61$ & $\begin{array}{l}1.28 \pm \\
0.33\end{array}$ & $2.54 \pm 0.49$ & $2.89 \pm 0.72$ & $\begin{array}{l}<.0001^{\mathrm{a}} \\
\end{array}$ \\
\hline $\begin{array}{l}\text { Preoperative } \\
\text { FBG }\end{array}$ & 77(93.9) & $7.15 \pm 1.51$ & $\begin{array}{l}2.50 \pm \\
0.51\end{array}$ & $8.81 \pm 1.54$ & $\begin{array}{l}10.09 \pm \\
1.83\end{array}$ & 0.430 \\
\hline $\begin{array}{l}\text { Hydration } \\
\text { amount }(\mathrm{mL})\end{array}$ & $60(73.2)$ & $220(93.2)$ & $\begin{array}{l}7.95 \pm \\
1.50\end{array}$ & $92(92.9)$ & $\begin{array}{l}1305.6 \pm \\
274.32\end{array}$ & 0.651 \\
\hline Aspirin (\%) & $73(89.0)$ & 186(78.8) & $1277.4 \pm$ & 72(72.7) & 25(92.6) & 0.642 \\
\hline Clopidogrel (\%) & $41(50.0)$ & 204(86.4) & & $81(81.8)$ & $19(10.4)$ & 0.132 \\
\hline $\begin{array}{l}\beta \text {-antagonist } \\
(\%)\end{array}$ & $10(12.2)$ & 137(58.1) & 151(76.6) & $49(49.5)$ & $16(59.3)$ & 0.950 \\
\hline ACEI/ARB (\%) & 25(30.9) & $20(8.5)$ & $172(87.3)$ & $7(7.1)$ & $2(74.1)$ & 0.978 \\
\hline Diuretics (\%) & $6(7.3)$ & $24(10.2)$ & $91(46.2)$ & 11(11.1) & $3(11.1)$ & $0.033^{a}$ \\
\hline CСВ (\%) & $45(54.8)$ & $93(39.4)$ & $13(6.6)$ & $40(40.4)$ & 13(48.1) & $0.011^{\mathrm{a}}$ \\
\hline $\begin{array}{l}\text { Hypoglycemic } \\
\text { agents (\%) }\end{array}$ & $\begin{array}{l}101.60 \pm \\
15.03\end{array}$ & $141(59.7)$ & 21(10.7) & 69(69.7) & $7(25.9)$ & $0.027^{a}$ \\
\hline $\begin{array}{l}\text { Insulin (\%) } \\
\text { PCl (\%) }\end{array}$ & $\begin{array}{l}113.46 \pm \\
16.46\end{array}$ & $\begin{array}{l}102.14 \pm \\
14.35\end{array}$ & $20(10.2)$ & $\begin{array}{l}109.94 \pm \\
15.66\end{array}$ & $\begin{array}{l}112.02 \pm \\
12.45\end{array}$ & $0.0001^{\mathrm{a}}$ \\
\hline
\end{tabular}




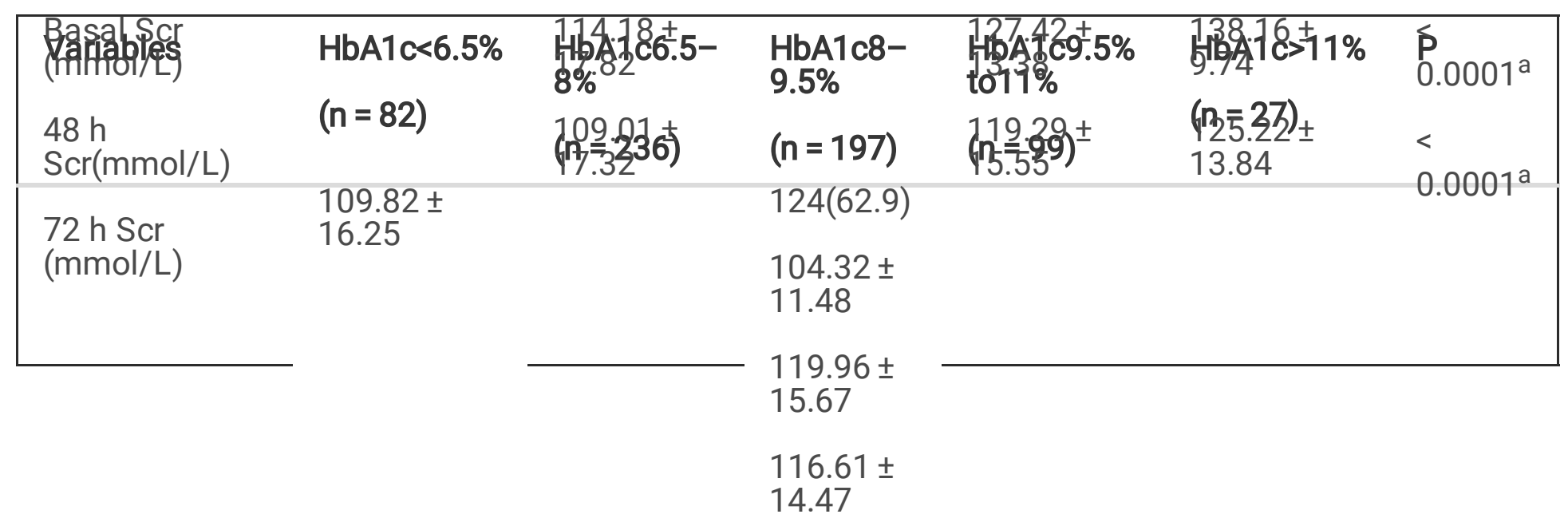

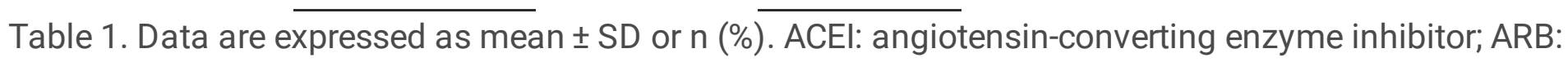
angiotensin receptor blocker; BMI: body mass index; TC: total cholesterol; TG: triglyceride; HDL-C: highdensity lipoprotein cholesterol; LDL-C: low-density lipoprotein cholesterol; LVEF: left ventricular ejection fraction; CCB: calcium channel blockers; FBG: fasting blood glucose; PCl: Percutaneous Coronary Intervention.

Comparison of Scr level and CIN incidence in each group

Patients with elevated HbA1C had higher basal Scr $(\mathrm{p}<0.0001)$, higher Scr values at $48 \mathrm{~h}$ and $72 \mathrm{~h}$ after $\mathrm{CAG} / \mathrm{PCl}(\mathrm{p}<0.0001$, Table 1). Multivariable logistic regression analysis was used to analyze the factors affecting $\mathrm{CIN}$. CIN was taken as the dependent variable, and factors that may affect the development of $\mathrm{CIN}$ (male, age, LVEF, Contrast volume, Hydration amount, ACEI/ARB, Diuretics, CCBs) were taken as independent variables. CIN was used as the dependent variable to exclude confounding factors. (OR = 2.019(1.362-3.209), $p=0.001$ )

The multivariate analysis confirmed the association between $\mathrm{HbA} 1 \mathrm{C}$ and the risk of $\mathrm{CIN}$ after adjustment for baseline confounding factors. The results showed that patients with elevated $\mathrm{HbA} 1 \mathrm{C}$ (above the median value $8.75 \%$ ) in the main high-risk subgroup had a higher risk of $\mathrm{CIN}$, such as $\mathrm{BMI}$ (BMI > $23.9 \mathrm{~kg} / \mathrm{m}^{2}$ : adjusted $\mathrm{OR}=1.909(1.196-3.047), \mathrm{p}=0.007 ; \mathrm{BMI} \leq 23.9 \mathrm{~kg} / \mathrm{m}^{2}$ : adjusted $\mathrm{OR}=2.631(0.922-$ 7.512), $p=0.071), L D L(L D L>2.59 \mathrm{mmol} / \mathrm{L}:$ adjusted $O R=1.797(0.949-3.403), p=0.072 ; L D L \leq$ $2.59 \mathrm{mmol} / \mathrm{L}:$ adjusted $O R=2.314(1.312-4.084), \mathrm{p}=0.004), \mathrm{FBG}(\mathrm{FBG}>7.1 \mathrm{mmol} / \mathrm{L}:$ adjusted $\mathrm{OR}=$ 1.592(0.973-2.604), $\mathrm{p}=0.064 ; \mathrm{FBG} \leq 7.1 \mathrm{mmol} / \mathrm{L}$ : adjusted $\mathrm{OR}=2.017(0.780-5.216), \mathrm{p}=0.148), \mathrm{PCl}$ (PCl: adjusted OR = 1.688(1.032-2.762), $p=0.037$; No PCl: adjusted OR=3.007(1.198-7.549), $p=0.019$ ). (Fig. 2)

Figure 2. 8.8\% is the median elevated HbA1C levels. BMI: body mass index; LDL-C: low-density lipoprotein cholesterol; FBG: fasting blood glucose; PCl: Percutaneous Coronary Intervention. 
The trend test was used to further demonstrate the relationship between $\mathrm{HbA} 1 \mathrm{C}$ levels and $\mathrm{CIN}$ incidence. It can be seen from the changes in Hazard Ratio (HR) $(1.000,1.248,1.553,2.625,5.829)$, with the increase of $\mathrm{HbA} 1 \mathrm{C}$ levels, the incidence of $\mathrm{CIN}$ increases gradually with a significant trend $(\mathrm{p}<0.0001)$. (Table 2$)$

Table 2

The logistic regression analysis and the trend test

\begin{tabular}{|llllll|}
\hline \multicolumn{7}{c|}{ Adjusted Hazard Ratio } \\
\hline HbA1c & $\begin{array}{l}\text { Participants, } \\
\mathrm{n}\end{array}$ & $\begin{array}{l}\mathrm{CIN}, \\
\mathrm{n}\end{array}$ & Model 1 & Model 2 & Model 3 \\
\hline$<6.5 \%$ & 82 & 9 & 1.000 (Reference) & 1.000 (Reference) & 1.000 (Reference) \\
$6.5-8 \%$ & 236 & 28 & $1.450(0.607-$ & $1.453(0.606-$ & $1.248(0.512-$ \\
$8-9.5 \%$ & 197 & 30 & $3.464)$ & $3.482)$ & $3.044)$ \\
$9.5 \%$ & 99 & 25 & $4.759)$ & $2.015(0.846-$ & $1.553(0.643-$ \\
to11\% & 27 & 13 & $3.642(1.483-$ & $3.800)$ & $3.804)$ \\
$>11 \%$ & - & - & $8.945)$ & $8.894)$ & $2.625(1.459-$ \\
P for & & & $9.753(3.268-$ & $9.791(3.260-$ & $5.718)$ \\
trend & & & $29.114)$ & $29.409)$ & $19.034)$ \\
& & & $<0.0001$ & $<0.0001$ & $<0.0001$ \\
\hline
\end{tabular}

Table 2. Model 1 was adjusted for age and male. Model 2 was adjusted for age, male, hypertension, contrast volume and hydration amount. Model 3 additionally was adjusted for BMI, LDL-C and PCI.

\section{Discussion}

In this study, we evaluated the relationship between preoperative glycosylated hemoglobin level and CIN incidence in patients undergoing $\mathrm{CAG} / \mathrm{PCl}$. This prospective and controlled trial showed that in diabetic patients undergoing $\mathrm{CAG} / \mathrm{PCl}$, elevated $\mathrm{HbA1C}$ is independently associated with the risk of $\mathrm{CIN}$, and with the increase of $\mathrm{HbA} 1 \mathrm{C}$ level, the incidence of $\mathrm{CIN}$ gradually increases. These results are of clinical significance, because Type 2 diabetes mellitus (T2DM) is a major risk factor affecting coronary artery disease (CAD), despite significant advances in the treatment of cardiovascular disease over the past 20 years, cardiovascular disease remains the leading cause of morbidity and mortality in patients with Type 2 diabetes mellitus, $75 \%$ of T2DM patients die as a consequence of cardiovascular diseases. $(22,23)$ With the improvement of PCl-related technology and equipment, $\mathrm{PCl}$ indications have become more extensive and complex, and the amount of surgery has increased year by year.(24) Patients who develop $\mathrm{CIN}$ have a greater risk for a number of non-renal complications including cardiac, vascular and systemic problems. For patients who develop CIN, treatment is limited to supportive measures until renal 
impairment resolves. It is important to evaluate the patient's blood glucose control before surgery and prevent postoperative $\mathrm{CIN}$, which not be viewed as a treatable and acceptable complication of contrast procedures. (25)

Diabetes is an important predisposing factor for $\mathrm{CIN}$, particularly in patients with renal functional impairment. Renal hypoxia, combined with the generation of reactive oxygen species, plays a central role in the pathogenesis of $\mathrm{CIN}$, and the diabetic kidney is particularly susceptible to intensified hypoxic and oxidative stress following the administration of contrast media. This complex pathophysiological mechanism includes a priori enhanced tubular transport activity, oxygen consumption, and the generation of reactive oxygen species. The regulation of vascular tone and peritubular blood flow may also be altered. In addition, microvascular and macrovascular diseases and chronic tubulointerstitial changes further compromise regional oxygen delivery, and renal antioxidant capacity might be hampered. In brief, both diabetes and contrast agents enhance ROS formation. They also hamper renal oxygenation, either directly or through increased generation of ROS.(10)The rat experiment showed that the CM-induced changes in diabetic rats indicate impaired renal function, oxidative stress, vascular dysfunction, and apoptosis, and were significance higher in intensity compared to non-diabetic rats.(26)

Clinical studies have proven that for patients with known and unknown diabetes, elevated blood glucose levels before surgery are a powerful and independent risk factor for CIN.(27)However, preoperative blood glucose level can only indicate the current blood glucose status, and is affected by stress and recent diet, which makes it difficult to accurately predict the prognosis. Measurement of HbA1c has been the traditional method for assessing glycemic control. From the existing structure and biosynthesis information, glycosylated hemoglobin is formed by the condensation of glucose and hemoglobin in red blood cells. The accumulation of glycosylated hemoglobin is a reflection of the average glucose concentration of red blood cells during their life cycle. Therefore, it can reflect the patient's recent blood sugar control status, and is not affected by external factors.(28) HbA1c level is closely related to the occurrence and development of coronary heart disease, and is also a prognostic factor for death after acute myocardial infarction(29)Prior to this, Barbieri $\mathrm{L}$ et al. have shown that $\mathrm{HbA} 1 \mathrm{c}$ level is related to the risk of CIN occurrence in without diabetic patients. (13)On this basis, we further studied whether HbA1c level also has an impact on CIN occurrence in diabetic patients, and obtained positive results.

\section{Limitations}

Our research excluded patients with severe renal insufficiency, receiving CM 14 days before operation, severe cardiac insufficiency, heart failure, malignant tumor, fever, and emergency PCI. Also excluded patients with anemia that may affect $\mathrm{HbA} 1 \mathrm{c}$. Although $\mathrm{HbA} 1 \mathrm{c}$ remains the reference marker for assessing glycemic control and predicting the risk of development of long-term complications, it is limited in that it cannot detect hypoglycemia or hyperglycemia on a daily basis and does not reflect rapid changes in daily glucose control.(12)Further studies on the pathogenesis and preventive measures are needed to completely prevent $\mathrm{CIN}$. 


\section{Conclusions}

Studies have shown that in diabetic patients undergoing CAG/PCl, elevated $\mathrm{HbA} 1 \mathrm{C}$ is independently associated with the risk of $\mathrm{CIN}$, and with the increase of $\mathrm{HbA1C}$ level, the incidence of CIN gradually increases. We consider that for patients with diabetes, controlling hemoglobin level has a preventive effect on postoperative $\mathrm{CIN}$, which is of great significance for patients undergoing elective PCl.

\section{Abbreviations}

$\mathrm{HbA1c}$

Glycosylated Hemoglobin

$\mathrm{CIN}$

Contrast-induced nephropathy

CAG

Coronary arteriography

$\mathrm{PCl}$

percutaneous coronary intervention

Scr

serum creatinine

ACEI

angiotensin-converting enzyme inhibitor;

ARB

angiotensin receptor blocker

$\mathrm{BMI}$

body mass index

TC

total cholesterol

TG

triglyceride

HDL-C

high-density lipoprotein cholesterol

LDL-C

low-density lipoprotein cholesterol

LVEF

left ventricular ejection fraction

CCB

calcium channel blockers

FBG

fasting blood glucose 


\section{Declarations}

Human and animal rights: All procedures performed in research involving human participants comply with the ethical standards of the institution and/or the National Research Council, and comply with the 1964 Declaration of Helsinki and its subsequent amendments or similar ethical standards.

Conflict of interest: There is no conflict of interest to be declared in this study

Informed consent: This study was approved by the Ethics Committee of Tianjin Chest Hospital, and written informed consent of all participants was obtained before registration

Availability of data and materials: The data set used and/or analyzed in the current research can be obtained from the corresponding author upon reasonable request

Funds: This study was funded by a Grant from the Tianjin Municipal Health and Family Planning Commission (Grant number: 14KG124).

Acknowledgements: we thank all the participants and enrolled patients of Tianjin Medical University in Tianjin of China for their cooperation.

Author's contribution: Zhang $\mathrm{H}$ completed the data collection and sorting; Fu $\mathrm{H}$ was mainly responsible for writing the article; Zhang $\mathrm{J}$ conducted the article writing guidance; Zhang P completed the related literature search; Yang S analyzed and explained the data; Fu X and Zeng Z were responsible for the blood sample collection and analysis of all patients. All authors take responsibility for all aspects of the reliability and freedom from bias of the data presented and their discussed interpretation

\section{References}

1. Mamoulakis C, Tsarouhas K, Fragkiadoulaki I, Heretis I, Wilks MF, Spandidos DA, et al. Contrastinduced nephropathy: Basic concepts, pathophysiological implications and prevention strategies. Pharmacol Ther. [Journal Article; Review]. 2017 2017-12-01;180:99-112.

2. Mehran R, Nikolsky E. Contrast-induced nephropathy: Definition, epidemiology, and patients at risk. KIDNEY INT. 2006 2006-01-01;69:S11-5.

3. Geenen RWF, Kingma HJ, van der Molen AJ. Contrast-induced nephropathy: pharmacology, pathophysiology and prevention. Insights into Imaging. 2013;4(6):811-20.

4. Chu K, Jung K, Lee S, Park H, Sinn D, Kim J, et al. Circulating Endothelial Progenitor Cells as a New Marker of Endothelial Dysfunction or Repair in Acute Stroke. STROKE. 2008;39(5):1441-7.

5. Liu Y, Tan N, Zhou YL, Chen YY, Chen JY, Chen J, et al. High-sensitivity C-reactive protein predicts contrast-induced nephropathy after primary percutaneous coronary intervention. J NEPHROL. [Journal Article; Research Support, Non-U.S. Gov't]. 2012 2012-05-01;25(3):332-40.

6. Lau A, Chung H, Komada T, Platnich JM, Sandall CF, Choudhury SR, et al. Renal immune surveillance and dipeptidase-1 contribute to contrast-induced acute kidney injury. J CLIN INVEST. 2018 2018-07- 
02;128(7):2894-913.

7. Qin Y, Yan G, Ma C, Tang C, Ma G. Effects of hyperglycaemia and elevated glycosylated haemoglobin on contrast-induced nephropathy after coronary angiography. EXP THER MED. 2018 2018-0101;16(1):377-83.

8. Chen Y, Fu N, Xu J, Yang S, Li S, Liu Y, et al. A simple preprocedural score for risk of contrast-induced acute kidney injury after percutaneous coronary intervention. CATHETER CARDIO INTE. 2014 201401-01;83(1):E8-16.

9. Toprak O, Cirit M, Yesil M, Bayata S, Tanrisev M, Varol U, et al. Impact of diabetic and pre-diabetic state on development of contrast-induced nephropathy in patients with chronic kidney disease. NEPHROL DIAL TRANSPL. 2007 2007-01-05;22(3):819-26.

10. Heyman SN, Rosenberger C, Rosen S, Khamaisi M. Why Is Diabetes Mellitus a Risk Factor for Contrast-Induced Nephropathy? BIOMED RES INT. 2013;2013:1-8.

11. Deedwania P, Kosiborod M, Barrett E, Ceriello A, Isley W, Mazzone T, et al. Hyperglycemia and acute coronary syndrome: a scientific statement from the American Heart Association Diabetes Committee of the Council on Nutrition, Physical Activity, and Metabolism. CIRCULATION. [Journal Article]. 2008 2008-03-25;117(12):1610-9.

12. Danne T, Nimri R, Battelino T, Bergenstal RM, Close KL, DeVries JH, et al. International Consensus on Use of Continuous Glucose Monitoring. DIABETES CARE. 2017;40(12):1631-40.

13. Barbieri L, Verdoia M, Schaffer A, Cassetti E, Di Giovine G, Marino P, et al. Pre-diabetes and the risk of contrast induced nephropathy in patients undergoing coronary angiography or percutaneous intervention. DIABETES RES CLIN PR. 2014;106(3):458-64.

14. 2. Classification and Diagnosis of Diabetes:Standards of Medical Care in Diabetes-2018. DIABETES CARE. 2017;41(Supplement 1):13-27.

15. Genuth S, Alberti KG, Bennett P, Buse J, Defronzo R, Kahn R, et al. Follow-up report on the diagnosis of diabetes mellitus. DIABETES CARE. [Consensus Development Conference; Journal Article; Review]. 2003 2003-11-01;26(11):3160-7.

16. Nijssen EC, Rennenberg RJ, Nelemans PJ, Essers BA, Janssen MM, Vermeeren MA, et al Prophylactic hydration to protect renal function from intravascular iodinated contrast material in patients at high risk of contrast-induced nephropathy (AMACING): a prospective, randomised, phase 3, controlled, open-label, non-inferiority trial. LANCET. [Clinical Trial, Phase III. Journal Article; Randomized Controlled Trial; Research Support, Non-U.S. Gov't]. 2017 2017-04-01;389(10076):1312-22.

17. Fu H, Zhang J, Zhang H, Zhang P, Fu X, Zeng Z, et al. Trimetazidine can prevent the occurrence of contrast-induced nephropathy after percutaneous coronary intervention in elderly patients with renal insufficiency. Perfusion. [Journal Article]. 2020 2020-09-10:1054038432.

18. Deek H, Newton P, Sheerin N, Noureddine S, Davidson PM. Contrast media induced nephropathy: a literature review of the available evidence and recommendations for practice. AUST CRIT CARE. [Journal Article; Review]. 2014 2014-11-01;27(4):166-71. 
19. Wang YC, Tang A, Chang D, Lu CQ, Zhang SJ, Ju S. Long-Term Adverse Effects of Low-Osmolar Compared With Iso-Osmolar Contrast Media After Coronary Angiography. AM J CARDIOL. [Comparative Study; Journal Article; Observational Study]. 2016 2016-10-01;118(7):985-90.

20. Cheng W, Zhao F, Tang CY, Li XW, Luo M, Duan SB. Comparison of iohexol and iodixanol induced nephrotoxicity, mitochondrial damage and mitophagy in a new contrast-induced acute kidney injury rat model. ARCH TOXICOL. [Comparative Study; Journal Article]. 2018 2018-07-01;92(7):2245-57.

21. Lubbers MM, Kock M, Niezen A, Galema T, Kofflard M, Bruning T, et al. lodixanol versus lopromide at Coronary CT Angiography: Lumen Opacification and Effect on Heart Rhythm-the Randomized IsoCOR Trial. RADIOLOGY. [Journal Article; Multicenter Study; Randomized Controlled Trial; Research Support, Non-U.S. Gov't]. 2018 2018-01-01;286(1):71-80.

22. Naito R, Miyauchi K. Coronary Artery Disease and Type 2 Diabetes Mellitus. INT HEART J. [Journal Article; Review]. 2017 2017-08-03;58(4):475-80.

23. Das SR, Everett BM, Birtcher KK, Brown JM, Januzzi JL, Kalyani RR, et al. 2020 Expert Consensus Decision Pathway on Novel Therapies for Cardiovascular Risk Reduction in Patients With Type 2 Diabetes. J AM COLL CARDIOL. 2020;76(9):1117-45.

24. Bhatt DL. Percutaneous Coronary Intervention in 2018. JAMA. [Journal Article; Review]. 2018 201805-22;319(20):2127-8.

25. Finn WF. The clinical and renal consequences of contrast-induced nephropathy. NEPHROL DIAL TRANSPL. 2006 2006-06-01;21(suppl_1):i2-10.

26. Hussien NI, Sorour SM, El-kerdasy HI, Abdelrahman BA. The glucagon-like peptide-1 receptor agonist Exendin-4, ameliorates contrast-induced nephropathy through suppression of oxidative stress, vascular dysfunction and apoptosis independent of glycaemia. CLIN EXP PHARMACOL P. 2018;45(8):808-18.

27. Stolker JM, McCullough PA, Rao S, Inzucchi SE, Spertus JA, Maddox TM, et al. Pre-Procedural Glucose Levels and the Risk for Contrast-Induced Acute Kidney Injury in Patients Undergoing Coronary Angiography. J AM COLL CARDIOL. 2010;55(14):1433-40.

28. Gabbay KH. Glycosylated hemoglobin and diabetes mellitus. Med Clin North Am. [Journal Article; Research Support US, Gov't PHS, Review]. 1982 1982-11-01;66(6):1309-15.

29. Cakmak M, Cakmak N, Cetemen S, Tanriverdi H, Enc Y, Teskin O, et al. The value of admission glycosylated hemoglobin level in patients with acute myocardial infarction. CAN J CARDIOL. [Journal Article]. 2008 2008-05-01;24(5):375-8.

\section{Figures}




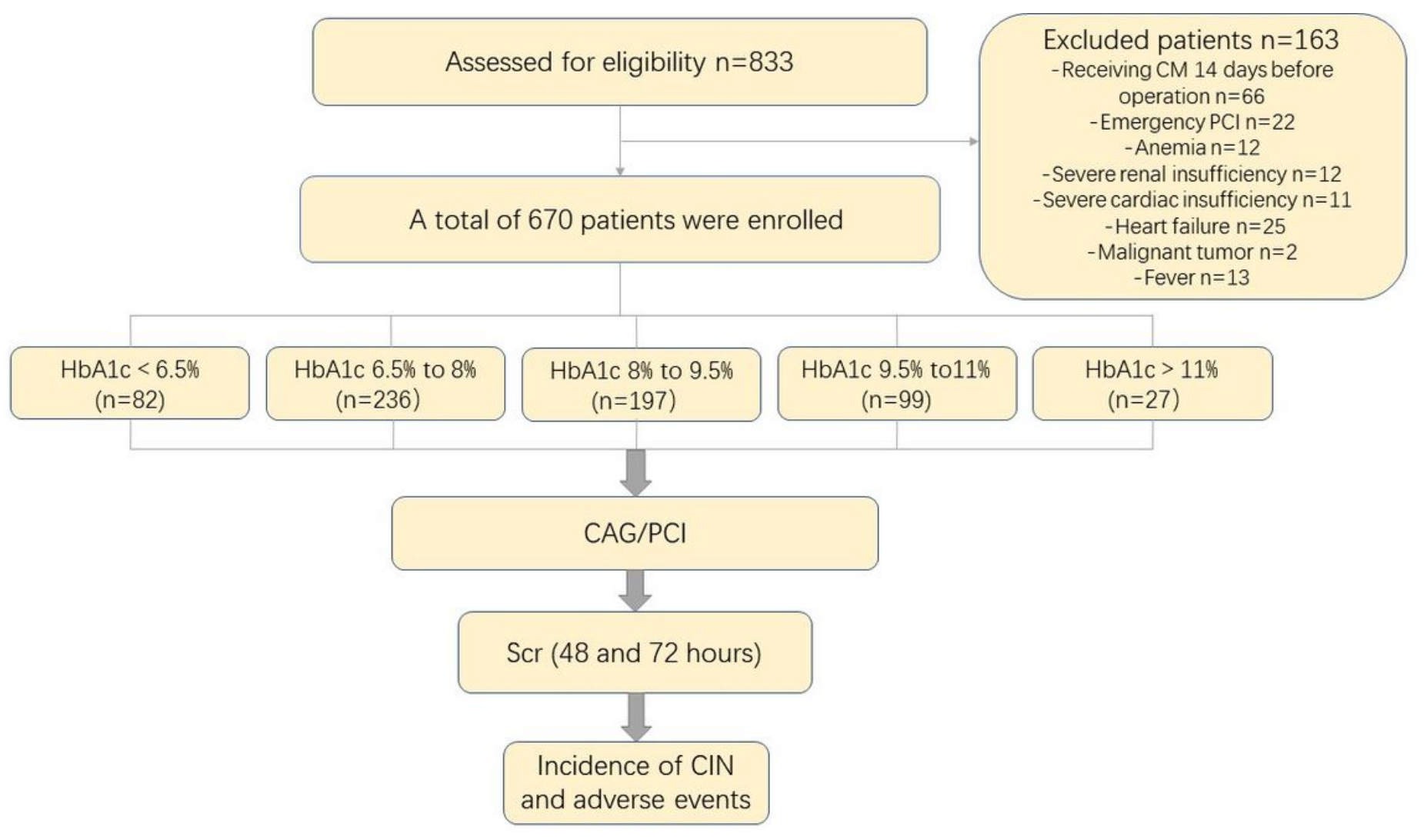

Figure 1

CAG: HbA1c: glycosylated hemoglobin; Coronary arteriography PCl; percutaneous coronary intervention; Scr: serum creatinine; CIN: contrast-induced nephropathy.

Risk of CIN

OR[95\% Cl]

OR $(95 \% \mathrm{Cl}) \quad$ P value

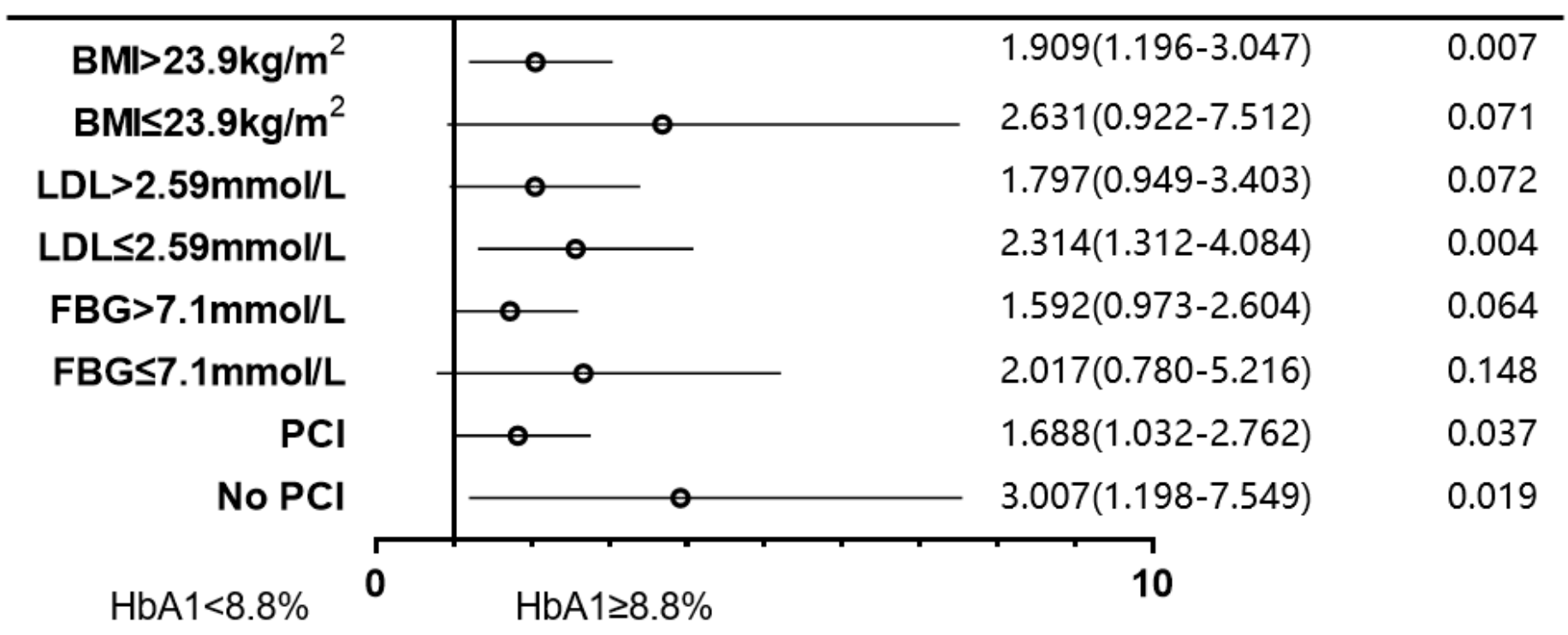




\section{Figure 2}

The association between $\mathrm{HbA} 1 \mathrm{C}$ and $\mathrm{CIN}$ risk after adjusting for baseline confounding factors $8.8 \%$ is the median elevated HbA1C levels. BMI: body mass index; LDL-C: low-density lipoprotein cholesterol; FBG: fasting blood glucose; PCl: Percutaneous Coronary Intervention. 